\title{
Research
}

\section{Dickeya dianthicola Is Not Vectored by Two Common Insect Pests of Potato}

\author{
Jonas K. Insinga ${ }^{1} \mid$ Andrei Alyokhin $^{1,+}$ (D) | Jianjun $\mathrm{Hao}^{2}$ | Tongling $\mathrm{Ge}^{2}$ (D) | \\ Nayara Fabiola Marangoni ${ }^{2}$ | Alex Baron ${ }^{1}$ |
}

\footnotetext{
${ }^{1}$ School of Biology and Ecology, College of Natural Sciences, Forestry, and Agriculture, University of Maine, Orono, ME 04469

${ }^{2}$ School of Food and Agriculture, College of Natural Sciences, Forestry, University of Maine, Orono, ME 04469
}

\footnotetext{
† Corresponding author: A. Alyokhin alyokhin@maine.edu
}

Accepted for publication 9 February 2021.
Funding

This project was supported by the United States Department of Agriculture-National Institute of Food and Agriculture Hatch project number ME032125 through the Maine Agricultural \& Forest Experiment Station and the Maine Potato Board.

Maine Agricultural and Forest Experiment Station Publication Number 3800.

$\boldsymbol{e}$-Xtra: A supplementary table, supplementary figure, and supplementary file are available online.

The author(s) declare no conflict of interest.

\begin{abstract}
Dickeya dianthicola (Samson) is an important pathogen causing blackleg disease of potato. Previous work suggested that insects might vector species of Pectobacteriaceae between plants but no conclusive work has confirmed this. Green peach aphids (Myzus persicae Sulzer) and Colorado potato beetles (Leptinotarsa decemlineata Say) are aggressive potato pests and related to known vectors of several species of bacteria other than $D$. dianthicola. This study sought to determine whether these insects vector $D$. dianthicola for potato infection. Neither insect species showed olfactory discrimination based on the presence of infection in laboratory tests but beetles were repelled by uninfected foliage treated with 2,3-butanediol, a primary Dickeya metabolite. Beetle recruitment to plants was not affected by their infection status; however, aphids preferred uninfected foliage when conspecifics were present. In the laboratory, neither insect acquired or transmitted $D$. dianthicola through feeding. In the field, neither insect's abundance was significantly correlated with disease spread. Overall, this study did not find indications that $D$. dianthicola is vectored by the tested insect species. Therefore, efforts to limit Dickeya spread should focus on sanitation, water management, and seed screening — not on the control of these insect species.
\end{abstract}

Keywords: blackleg, butanediol, Dickeya dianthicola, Leptinotarsa decemlineata, Myzus persicae, potato, olfactometry, transmission

Several species of Gram-negative, nonspore-forming, anaerobic enterobacteria of the related genera Dickeya and Pectobacterium are known to cause blackleg, aerial stem rot, slow wilt, and tuber soft rot in potato (Borman et al. 1944; Czajkowski et al. 2011; Laurila et al. 2008; Ma et al. 2007; Tsror et al. 2009). In recent years, growers have struggled against recently identified Dickeya spp. (Charkowski 2018; Toth et al. 2011). Dickeya dianthicola (Samson) is responsible for most damage in northeastern America, where it has remained a significant problem since a major outbreak in 2014 (Charkowski 2018; Jiang et al. 2016). 
Dickeya and Pectobacterium spp. can survive as free-living saprophytes on decaying organic matter or asymptomatically on the roots and leaves of certain plant species, and travel through water films to infect susceptible plants through open lenticels or wounds (Czajkowski et al. 2010b; Toth et al. 2003). In theory, anything that can carry and spread contaminated plant debris or water or that wounds plants can potentially promote the dissemination of soft rot bacteria, including Dickeya and Pectobacterium spp. However, there has been comparatively little work investigating whether insect pests are capable of transmitting Dickeya spp. between host plants.

Drosophilid flies have been shown to transmit blackleg caused by Pectobacterium (Waldee) (Kloepper et al. 1981; Molina et al. 1974). Similarly, the anthomyiid fly Delia radicum L. transmitted Pectobacterium spp. to crucifers (Baur et al. 1998) and, together with other Delia spp., has been recently suggested to play a role in the transmission of this and other soft rot bacteria in potato fields (Rossmann et al. 2018). Furthermore, Dickeya dadantii is capable of infecting pea aphid Acyrthosiphon pisum (Harris) (Costechareyre et al. 2012; Grenier et al. 2006). Young, winged aphids were less sensitive to the impacts of infection than wingless adults (Grenier et al. 2006). This suggests the possible existence of a coevolutionary relationship, where bacteria are less virulent to winged aphids that may serve as vectors. It also implies a possibility of circulative rather than phoretic transmission. The same aphid species has been also shown to transmit Pseudomonas syringae (Van Hall), a bacterium unrelated to the family Enterobacteriaceae, between fava bean plants (Stavrinides et al. 2009). While feeding on bean plants colonized by epiphytic bacteria, $A$. pisum acquired $P$. syringae, which subsequently colonized their digestive tract, multiplied, and was excreted in the aphid honeydew (Stavrinides et al. 2009). However, actual transmission of Dickeya spp. by aphids has never been demonstrated. The nature of the relationship between Pectobacterium spp. and flies is very different from the specific pathogenicity of $D$. dadantii to pea aphids (Costechareyre et al. 2012), with the latter much less likely to result in transmission.

Dickeya spp. derive energy through fermentation of plantderived carbohydrates released during host tissue necrosis, and a primary metabolite resulting from this is 2,3-butanediol (Effantin et al. 2011). Although it has not been evaluated within the context of Dickeya-insect relationships, 2,3-butanediol is known to be a component of floral and decompositional volatiles that various insects use to locate sources of food (Becher et al. 2012; Bengtsson et al. 2009). The association between drosophilids and 2,3-butanediol is evidently so strong that several plant species in the genus Ceropegia L. secrete volatile blends which contain this compound in order to lure these and other decay-associated flies for the purpose of pollination (Heiduk et al. 2017).

The green peach aphid Myzus persicae (Sulzer) and the Colorado potato beetle Leptinotarsa decemlineata (Say), are abundant and serious pests in most potato-growing areas of the world. Green peach aphids transmit over 100 viral diseases (Capinera 2017). They are not known as vectors of plant-pathogenic bacteria but have been shown to transmit a human-pathogenic bacterium, Salmonella enterica, between lettuce plants (Soto-Arias et al. 2014). Colorado potato beetles are not known to transmit any disease. However, other members of the family Chrysomelidae have been reported to vector related bacteria Pantoea stewartii (Margaert) (Esker and Nutter 2003; Menelas et al. 2006; Roper 2011) and Erwinia tracheiphila (Smith) (Nadarasah and Stavrinides 2011; Sasu et al. 2010; Shapiro et al. 2012).

The main goal of this study was to determine whether green peach aphids and Colorado potato beetles transmit $D$. dianthicola.
Our specific objectives were to measure their responses to infected and uninfected foliage, to determine whether they can acquire and transmit $D$. dianthicola between potato plants, and to correlate their abundance in the field with the proportion of harvested tubers infected with $D$. dianthicola.

\section{MATERIALS AND METHODS}

\section{Maintenance of insects and plants}

The rearing of insects used in this research follows protocols described in detail by Galimberti and Alyokhin (2018). Colorado potato beetles ( $L$. decemlineata) were maintained in a colony from wild-caught adults collected from potato fields at the University of Maine's Aroostook Experimental Farm in Presque Isle, ME, and supplemented annually with individuals from that location to maintain genetic diversity. Colorado potato beetles were kept in insect cages ( 50 by 50 by $90 \mathrm{~cm}$ ) in a greenhouse on potted potato plants (Superior). Green peach aphids ( $M$. persicae) were obtained from a laboratory colony reared from wild-caught individuals originating from the same fields on Aroostook Research Farm and also supplemented with wild-caught individuals every year. Green peach aphids were raised on excised potato foliage (Superior) inserted in vials of water taped to the floors of ventilated colony enclosures built from clear plastic jars (approximately 1.9 liter) and deli cups (1 liter) and kept at $25^{\circ} \mathrm{C}$ and a photoperiod of $16 \mathrm{~h}$ of light and $8 \mathrm{~h}$ of darkness.

\section{Culturing $D$. dianthicola}

To prepare liquid inoculum, $100 \mu \mathrm{l}$ of liquid-suspended bacterial culture of $D$. dianthicola ME30 (Jiang et al. 2016) was cultured in $30 \mathrm{ml}$ of tryptic soy broth (TSB), for $24 \mathrm{~h}$ at $30^{\circ} \mathrm{C}$ on an incubating orbital shaker. To isolate bacteria for longterm storage, $100 \mu \mathrm{l}$ of that liquid inoculum was applied to 100-by-15-mm polystyrene Petri dishes containing crystal violet pectin (CVP) agar made following Hélias et al. (2011). The liquid applied to the media was spread evenly using a flamesterilized glass cell spreader. Each plate was then sealed using Parafilm and placed within an incubator (Series 33 Controlled Environment Chamber; Percival Scientific Inc., Perry, IA, U.S.A.) set to either 28 or $30^{\circ} \mathrm{C}$ with a photoperiod of $16 \mathrm{~h}$ of light and $8 \mathrm{~h}$ of darkness for $48 \mathrm{~h}$ (Czajkowski et al. 2010b, 2015). After incubation, each plate was inspected for discrete colonies which caused cavitation of the medium. A single colony was selected and added to liquid TSB and incubated at $30^{\circ} \mathrm{C}$ for $24 \mathrm{~h}$ to create inoculum. Inoculum $(1 \mathrm{ml})$ was added to 2-ml microcentrifuge tubes with attached snap caps together with $1 \mathrm{ml}$ of $50 \%$ glycerin. The suspension was then homogenized for $5 \mathrm{~s}$ on a digital pulsing vortex machine, labeled, and placed in $-80^{\circ} \mathrm{C}$ storage until needed.

\section{Plant maintenance and inoculation}

Potato plants were grown in $25.4-\mathrm{cm}$ plastic pots from seed tubers (Superior) produced by the Aroostook Research Farm in Presque Isle, ME. When potato stems were at least 25 to 30 $\mathrm{cm}$ tall and possessed mature leaves, wounds were made using a sterile pipette tip (one tip per plant) in each stem by repeated puncturing. Stems too small to support such wounding were removed. Depending on the experiment (see below), either 10 or $100 \mu \mathrm{l}$ of liquid was injected into the wound of each stem 
(Czajkowski et al. 2010a). Nonsterile distilled water was used for control treatments.

Following injection, each stem was wrapped with Parafilm to seal the wounds and avoid desiccation. Plants were allowed to incubate at room temperature to induce slow wilt when they needed to be utilized over several weeks or incubated at 28 or $30^{\circ} \mathrm{C}$ in an incubator (see above) when rapid development of symptoms was needed. Plants were incubated at 28 to $30^{\circ} \mathrm{C}$ for a maximum of 7 days but were removed to continue incubating at room temperature if the disease had caused the plant's stems to collapse before the end of the incubation period to ensure that useable foliage was available for experiments. During incubation, plants were placed in plastic planter saucers and watered excessively from below to induce physiological stress upon the plants, a factor which benefits Dickeya spp. (Czajkowski et al. 2011).

\section{Molecular confirmation of infection}

Tissue was excised with a sterile knife from the bottom $2 \mathrm{~cm}$ of 1 to 3 stems per potato plant. Tissue expressing lesions was sampled preferentially. When no lesions were present on plants that had received injections, the sampled tissue included the site of injection. Excised tissue was placed in approximately $3 \mathrm{ml}$ of sterile distilled water for at least $5 \mathrm{~min}$ to allow bacteria to stream into the water from the cut ends of the stem tissue (NPC 2017). When sampling DNA from tubers, 30 to $50 \%$ of a tuber's skin was collected from each tuber using a sterile vegetable peeler. Tubers less than $5 \mathrm{~cm}$ in length were cut in half, proximal to the distal end, and one piece was crushed and placed in water instead of peeling. Peels and crushed tuber pieces were placed in individual sealable plastic sandwich bags with enough sterile distilled water to cover them. The bags were sealed and incubated at $30^{\circ} \mathrm{C}$ for 24 to $48 \mathrm{~h}$.

An aliquot of $200 \mu \mathrm{l}$ of bacterial suspension was collected for DNA extraction, which was done using the MP Bio FastDNA Kit following the manufacturer's instructions (MP Biomedicals, Santa Ana, CA, U.S.A.). The extracted DNA was adjusted to 20 and 30 $\mathrm{ng} / \mu \mathrm{l}$ and used as a template in a PCR with the primer pair pelADE1 (GATCAGAAAGCCCGCAGCCAGAT) and pelADE2 (CTGTGGCCGATCAGGATGGTTTTGTCGTGC) (Nassar et al. 1996). Details of the PCR system are provided in Supplementary File S1. These methods for DNA extraction and PCR assay have been approved by the United States Department of Agriculture Animal and Plant Health Inspection Service and are currently considered to be standard procedures for Dickeya detection (NPC 2017). Although density of bacteria in asymptomatic plants is usually low, in most cases not exceeding $10^{3}$ cells $\mathrm{g}^{-1}$ of plant tissue (Czajkowski et al. 2015), PCR assays are rather sensitive and have been shown to detect Dickeya spp. at concentrations of 10 cells $\mathrm{ml}^{-1}$ of plant extract or $10^{2}$ cells $\mathrm{g}^{-1}$ of plant tissue (Potrykus et al. 2014). Furthermore, they have a good correlation with subsequent disease expression in the field, producing only between 1.3 and $3.25 \%$ of false-negative results (Tsror et al. 2012).

\section{Insect response to foliar volatiles from Dickeya-infected plants}

Influence of various odor baits on adult Colorado potato beetle behavior was tested in a custom-built wind tunnel (Fig. 1A) maintained within an active, ventilated fume hood to prevent odors from lingering between trials. Adult Colorado potato beetles were tested individually for $30 \mathrm{~min}$ or until they crossed a line $22 \mathrm{~cm}$ upwind from the starting point. Between the trials, the interior of the wind tunnel was cleaned with acetone. In all, 20 individual Colorado potato beetles (10 males and 10 females) were tested for each of the following baits: $10 \mathrm{ml}$ of 2,3-butanediol (Sigma-Aldrich, St. Louis, MO, U.S.A.), $10 \mathrm{ml}$ of distilled water, an excised potato leaflet from an uninfected intact plant, and an excised leaflet to which $10 \mathrm{ml}$ of 2,3-butanediol was applied. Excised foliage was used because it has been repeatedly shown to be more attractive compared with intact potato plants (Bolter et al. 1997; Landolt et al. 1999). The organic volatile 2,3-butanediol is a major fermentative byproduct of Dickeya metabolism (Effantin et al. 2011) and was tested as a proxy for infected foliage. Dose was selected based on the amounts demonstrated to have biological activity toward the sorghum chafer Pachnoda interrupta (Olivier) (Bengtsson et al. 2009). A follow-up experiment was conducted following the same procedures but comparing an excised leaflet from an infected potato plant and an excised leaflet from an uninfected intact plant. Baits were placed in glass Petri dishes (Pyrex, Greencastle, PA, U.S.A.) that were swapped between trials.

Green peach aphids were tested in a Y-tube olfactometer (Analytical Research Systems, Gainesville, FL, U.S.A.) because they were too small to use with the wind tunnel (Fig. 1B) (see Narayandas and Alyokhin [2006a] for a detailed description of the system). One wingless adult aphid was given the choice between baited and unbaited air currents. Although winged aphids are generally considered to be more important as disease vectors, wingless aphids are usually much more numerous than winged conspecifics. They are also more mobile than is usually acknowledged and can infect a substantial number of plants (Alyokhin and Sewell 2003; Narayandas and Alyokhin 2006b). Aphids were given $60 \mathrm{~min}$ to walk at least halfway up one of the two arms, at which time the trial ended and the results were recorded. If the aphid traveled up the baited arm, it was interpreted as having a "positive response." Between each trial, all glass equipment was rinsed with acetone to remove any odor residues.

In the first experiment, 20 aphids were individually tested using excised foliage taken either from plants that had been given traumatic injections of $D$. dianthicola ME30 or from uninfected plants. In the second experiment, 20 aphids were individually exposed to foliage that had been taken either from plants infected using traumatic injection with $D$. dianthicola ME30 or from plants which had been given traumatic injections of sterile distilled water. Although mechanical damage due to excision may diminish appeal of potato foliage to aphids, damaged leaves remain attractive (Ameline et al. 2007). Because the small size of aphids made their reliable recovery from whole plants in other experiments that comprised this study highly problematic (see below), for consistency we also used excised leaflets for olfactometry. The data were analyzed using a $\chi^{2}$ test using the $\mathrm{R}$ package (R Core Team, Vienna, Austria).

\section{Insect recruitment to foliage from infected plants in artificial arenas}

Colorado potato beetle choice between infected and uninfected potato plants was tested in outdoor arenas on the Aroostook Research Farm in Presque Isle, ME (Booth and Alyokhin 2016). Each arena measured 4 by 3 by $8 \mathrm{~m}$ and was constructed of wood and aphid mesh screen with a false bottom covered in field soil. Two potted potato plants were inserted into two holes spaced $1 \mathrm{~m}$ apart. One plant had been inoculated with $D$. dianthicola ME30 using traumatic stem injections and incubated for 7 days at room temperature. The other 


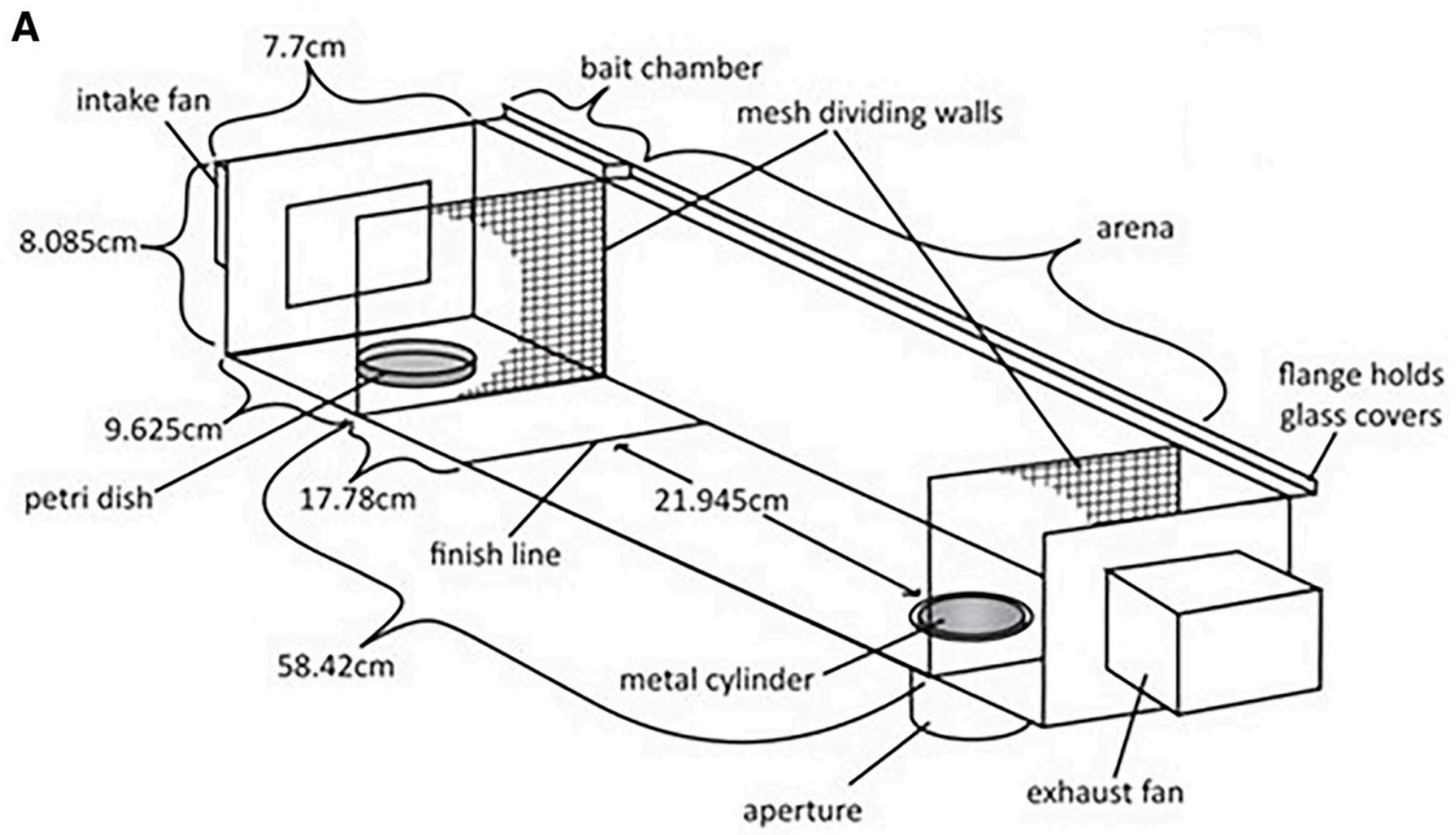

B

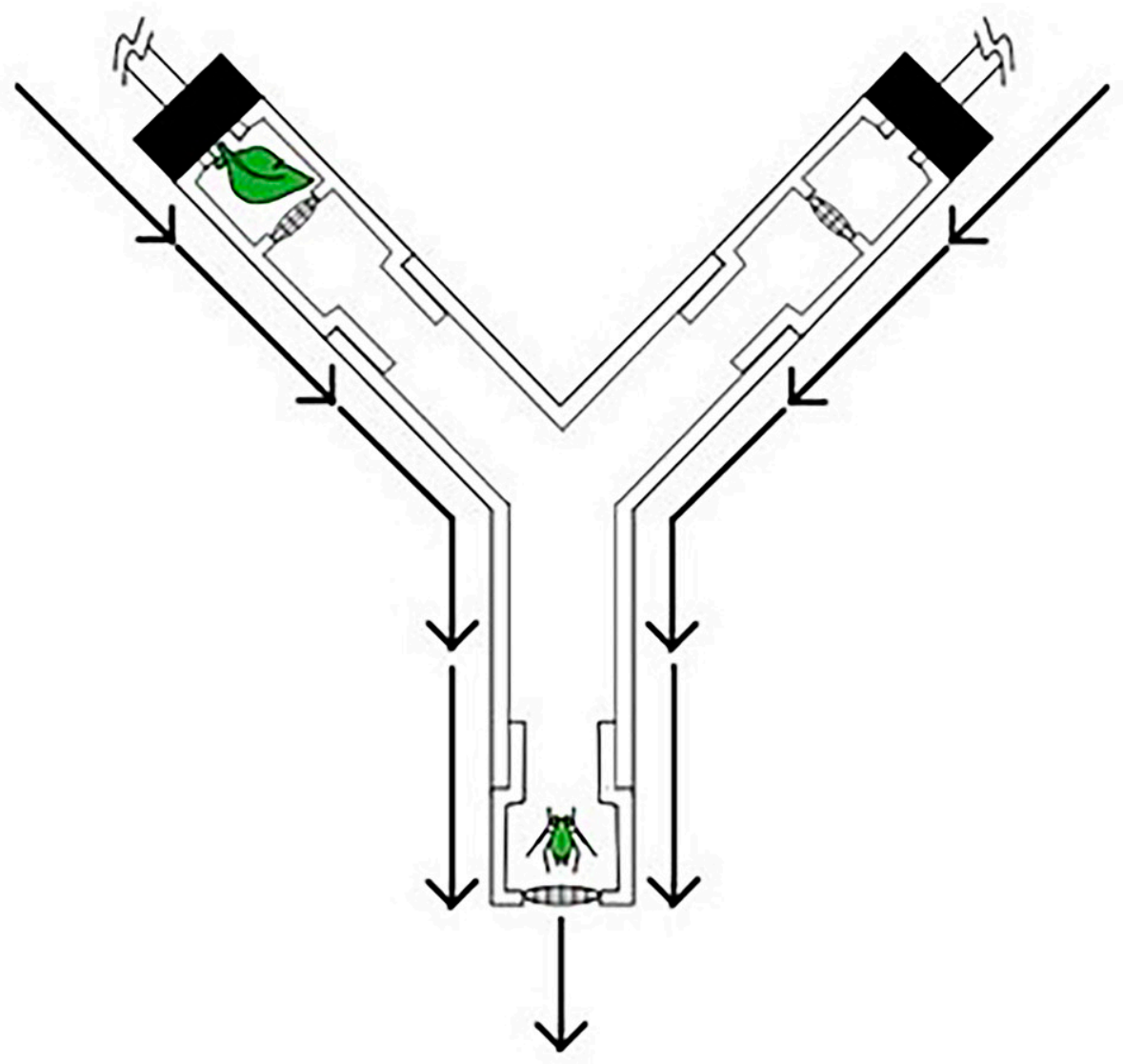

FIGURE 1

Laboratory equipment used for olfactometry experiments. A, Wind tunnel used to test Colorado potato beetle responses and B, olfactometer used to test green peach aphid responses. 
was an uninfected intact plant. Ten beetles (five of each sex) were released equidistant between the two plants. After $24 \mathrm{~h}$, each cage was checked and the number of beetles on each plant was counted. Collected data were analyzed using Welch's two-sample $t$ test in $\mathrm{R}$ (R Core Team). The experiment was replicated nine times.

Because of their small size, aphid recruitment was tested in arenas made of 100-by-15-mm Petri dishes lined with moistened paper towels. Two excised leaflets, one from a plant inoculated with $D$. dianthicola and one from an uninfected plant, were placed on the opposite sides of the dish. In the first experiment, 10 wingless adult green peach aphids were placed in the center of the dish, equidistant between the two excised leaflets. In the second experiment, only one wingless adult aphid was released in each dish to control for possible communication among the released aphids. The closed Petri dish was then sealed with Parafilm (Bemis, Neenah, WI, U.S.A.) to prevent escape and desiccation and left in an incubator set to $30^{\circ} \mathrm{C}$ and a photoperiod of $16 \mathrm{~h}$ of light and $8 \mathrm{~h}$ of darkness. After $24 \mathrm{~h}$, the number of aphids on each leaflet was tallied. Both experiments were replicated 30 times. Data from both grouped and individual aphid experiments were analyzed using the Wilcoxon test in R (R Core Team).

\section{Laboratory uptake and transmission of $D$. dianthicola}

Plants either infected with $D$. dianthicola or uninfected were obtained as described above. Experimental design, including the number of released individuals, stage of infection, and duration of the acquisition feeding period and the inoculation feeding period, are shown in Figure 2. Colorado potato beetles were allowed to feed on infected plants and transferred to uninfected plants; then, the presence of $D$. dianthicola was tested in plants and beetles using PCR and plating as described above (Fig. 2A). Because preliminary tests proved that recovery of green peach aphids directly from plants was unreliable, they were fed on leaflets excised from each infected plant instead (Fig. 2B). Because of their small size, green peach aphids also did not yield enough tissue to do plating. Therefore, they were tested only with PCR. For both aphids and beetles, insects which died during a trial were also tested for D. dianthicola.

In total, 13 replications using Colorado potato beetles and 11 replications using green peach aphids were completed. Aphid mortalities observed within the Petri dishes were compared using an analysis of variance (ANOVA) with R (R Core Team), with infection status of host plant and replication as main effects. Due to lack of measurable responses (see Results below), it was impossible to analyze other data.

\section{Field uptake and transmission of $D$. dianthicola}

Experiments were conducted on the Aroostook Research Farm in Presque Isle, ME during the 2017 and 2018 field seasons. A field measuring 152 by $30 \mathrm{~m}$ was broken into five replication blocks of four plots of four 15.24-m rows each. Fifty seed tubers (Katahdin) were planted in each row. After plants had reached approximately $25 \mathrm{~cm}$ in height, four plants per row were randomly selected and injected with $10 \mu \mathrm{l}$ of TSB-based Dickeya inoculum in each stem, as outlined above. Wounds were wrapped in parafilm to prevent desiccation and the position of each injected plant was marked using lawn flags.

After injections, each plot within each block received a different pest management prescription. Aphids were suppressed in one plot using pymetrozine (Fulfill; Syngenta Crop Protection Inc., Greensboro, NC, U.S.A.), another plot was treated with spinosad (Blackhawk Naturalyte Insect Control, Dow AgroSciences, Indianapolis, IN, U.S.A.) to suppress Colorado potato beetles, a third plot was treated with both chemicals to suppress both aphids and Colorado potato beetles, and a fourth plot served as a control by receiving no insecticide applications. Treatments were randomized between replications, resulting in a randomized complete block design. Both years, plants were irrigated to adjust weekly precipitation to at least $2.54 \mathrm{~cm}$ and were top killed prior to harvest.

In 2017, plants were injected twice, once on 7 July and again on 20 July due to a high rate of failure among plants to develop symptoms of the disease after one injection. Second injections were only given to those plants which were previously injected and failed to develop blackleg symptoms. The parafilm was not used during the second round of injections because it did not appear to have an impact on the success of infection. Each plot was inspected weekly for plants expressing signs of Dickeya infection, as well as to record the level of defoliation by pests and the abundances of Colorado potato beetles and aphids.

To document the abundance of aphids, 10 flagged plants and 10 unflagged plants were randomly chosen from each plot during weekly plot inspection. From each plant, the numbers of aphids found on three leaves (one near the bottom, one from the middle, and one at the top) of a single stem were recorded. The numbers of two potato-colonizing aphid species were recorded: green peach aphids and potato aphids (Macrosiphum euphorbiae Thomas) (UMCE 2016). When analyzing the abundance of the insect pests, the aphid species were pooled due to their low abundance.

As with aphids, Colorado potato beetles were recorded from 10 randomly selected flagged plants and 10 randomly selected unflagged plants from each plot; however, their numbers were recorded from entire plants instead of from three leaves per plant. Numbers of egg masses, "small" (first and second instar) larvae, "large" (third and fourth instar) larvae, and adults were recorded on each plant. Finally, the level of defoliation of each plot was documented as a visually estimated percentage of the ground covered by the canopy of an entire plot (Alyokhin et al. 2005).

Lawn flags were used to mark the locations of symptomatic plants. Those flags were labeled to identify the date symptoms were first observed. All flagged plants were harvested individually and tubers were bagged by plant with a plant-specific code designating whether the parent plant had received injections and whether the plant had displayed symptoms of blackleg disease. The remaining tubers were pooled by plot, and five tubers from each pool were randomly collected and bagged for sampling.

In the lab, 128 tubers from 17 plants underwent DNA extraction and PCR to determine whether the injected plants acquired Dickeya spp. within their daughter tubers, whether all daughter tubers from an infected plant were infected, and whether plants which did not display signs of infection produced infected tubers. Harvested tubers which had not been sampled for Dickeya were replanted in 2018 to observe whether the resulting plants expressed signs of infection. In total, 73 tubers from 10 plants were planted in plastic pots in the greenhouse using methods and materials identical to the production of plants for use in insect rearing. The remaining tubers were planted in a field at the Aroostook Research Farm. The plant-back field was checked every other week and the numbers of symptomatic plants were recorded. 
A
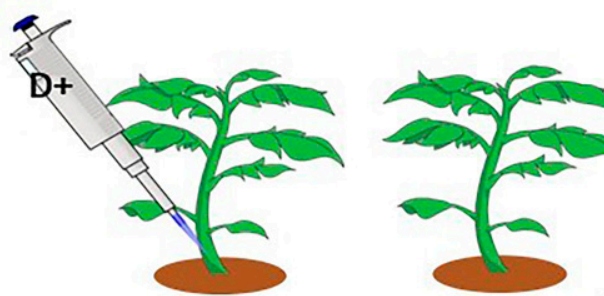

A

Step 1

Inject $D$. dianthicola strain ME30-derived inoculum into plant A.

Test plant B for Dickeya using PCR.

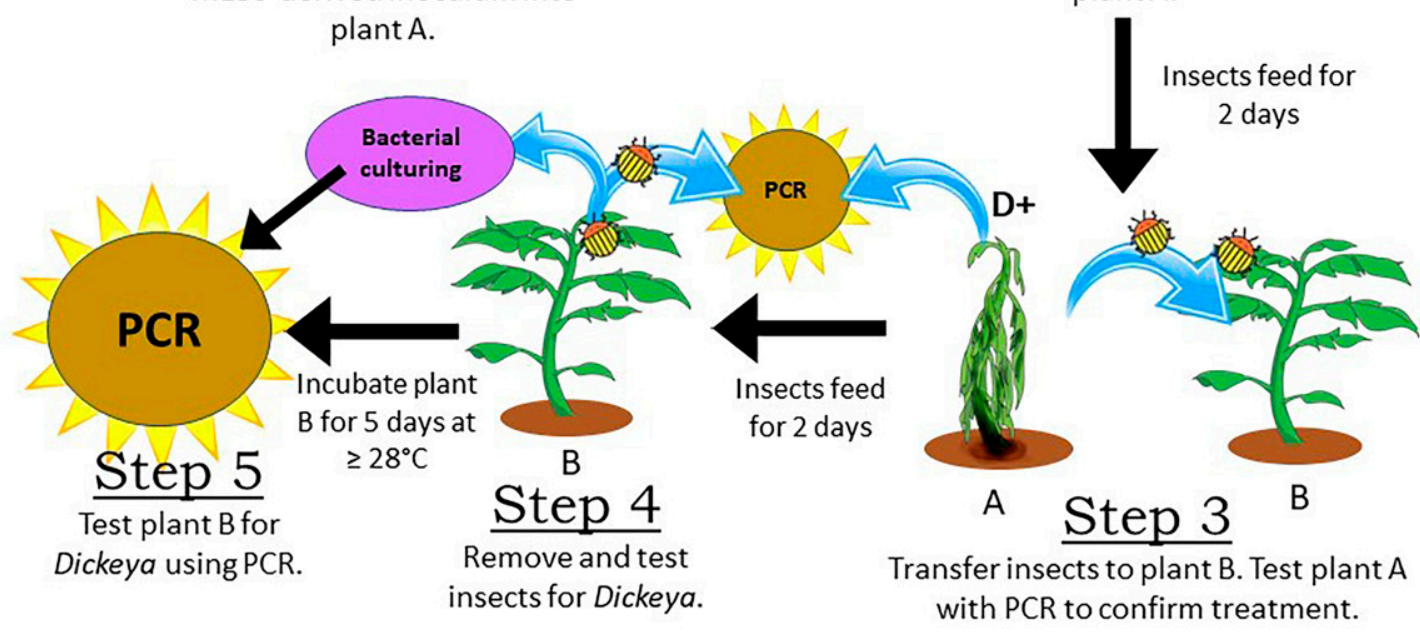

B
Incubate plant A for 5 days at $\geq 28^{\circ} \mathrm{C}$

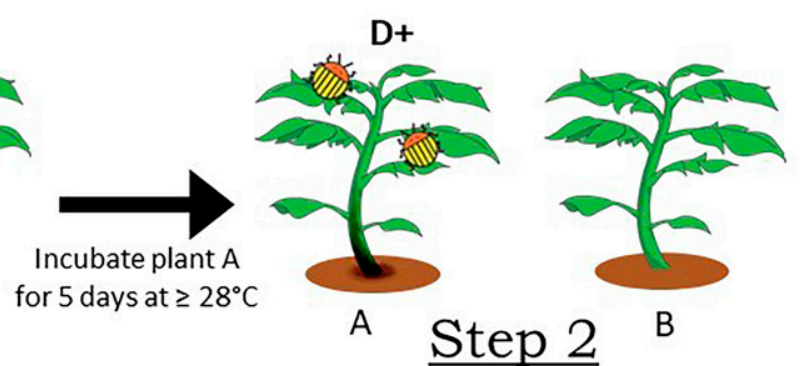

Introduce 5 males and 5 females to plant $A$.

B

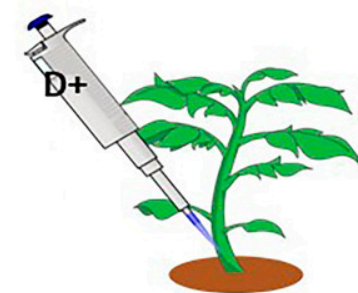

A

Step 1

Inject $D$. dianthicola strain ME30-derived inoculum into plant A.

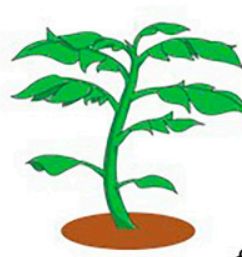

B
Incubate plant A for 5 days at $\geq 28^{\circ} \mathrm{C}$

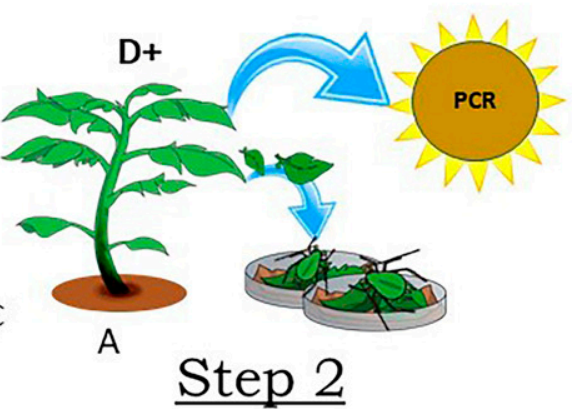

Divide six leaves from plant $A$ and 60 aphids between two Petri dishes. Test plant A to confirm treatment.

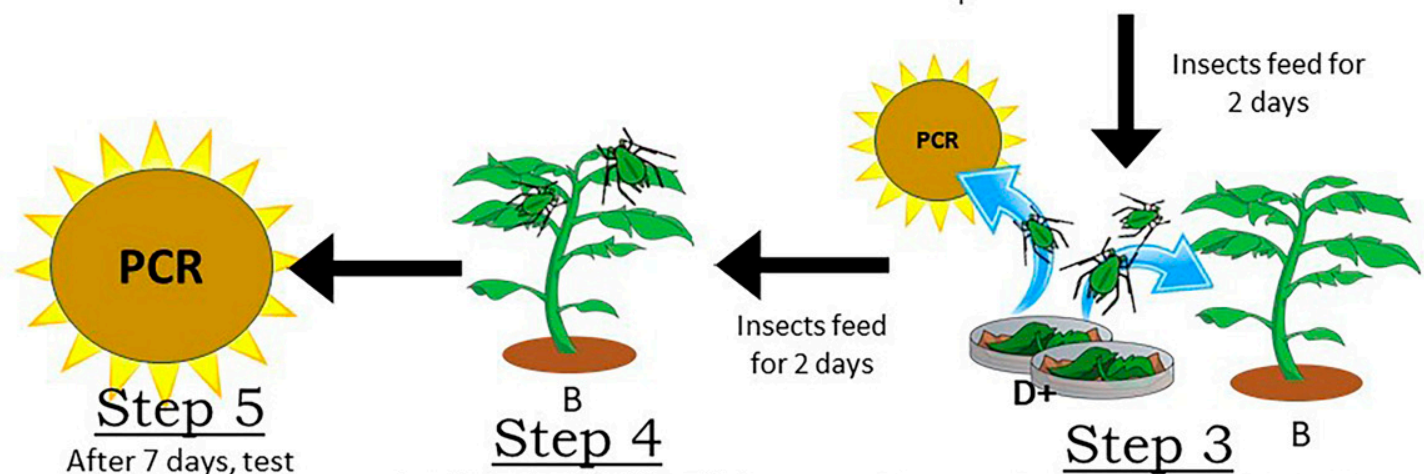

After 7 days, test plant B for Dickeya using PCR.
Incubate plant B with aphids for 7 days under greenhouse conditions.
Count and test dead aphids for Dickeya. Test five live aphids \& transfer the rest to plant B.

FIGURE 2

Design of laboratory experiments testing uptake and transmission of Dickeya dianthicola. A, Colorado potato beetle experiment and B, green peach aphid experiment. 
In 2018, plants were only injected once due to an observed higher rate of success in symptom development when compared with the previous year. The injections done during the 2018 season were carried out over the course of two consecutive days (17 and 18 July) because inclement weather did not allow them to be completed on a single day. For consistency with the 2017 season, Parafilm was still used to wrap wounds during both days of injecting in 2018. The main focus was placed on the infection of harvested tubers rather than on the appearance of symptomatic plants during the growing season and on insect abundance on symptomatic and asymptomatic plants investigated in 2017. Therefore, protocols on collecting field data were less detailed than in the previous year, and their main purpose was establishing the presence or absence of corresponding damage. Colorado potato beetle life stages were counted on 3 and 11 July. Defoliation data were collected on 30 July, and aphid data were collected on 10 August. Plants expressing blackleg symptoms were counted on 3 August. Timing for insect counts was selected based on the perceived peaks of their densities.

During the 2018 harvest, all symptomatic plants were harvested individually and their tubers were bagged individually and sampled for Dickeya spp. The remaining tubers in the field were harvested and pooled by plot. In the lab, 10 tubers were selected at random from each of those 20 pools and tested for Dickeya infection, following the same protocol as in 2017.

Data were analyzed using the SAS statistical package (version 9.4; SAS Institute, Cary, NC, U.S.A.). Normality of the distribution of field data were tested by the Shapiro-Wilk test with PROC UNIVARIATE. Nonnormal data were transformed using rank transformations with PROC RANK. Field data collected in 2017 were analyzed using repeated-measure ANOVA with PROC MIXED. Numbers of insects on symptomatic and asymptomatic plants were compared using Wilcoxon's test using PROC UNIVARIATE. Stepwise multiple regression analysis was used to test a relationship between mean abundances of Colorado potato beetle life stages and the number of symptomatic plants within each plot. Field data collected in 2018 were analyzed using ANOVA with PROC GLM.

\section{RESULTS}

\section{Insect response to foliar volatiles from Dickeya-infected plants}

Uninfected potato foliage treated with 2,3-butanediol elicited the least response from Colorado potato beetles (Fig. 3) $\left(\chi^{2}=12.24\right.$, df $\left.=3, P=0.0066\right)$. The beetles did not discriminate between foliage from infected and uninfected plants $\left(\chi^{2}=\right.$ 0.46 , df $=1, P=0.4996$ ), with $67.5 \%$ of them moving upwind in the wind tunnel.

When the plant from which control foliage was collected did not receive any injections, the number of aphids moving upwind did not differ significantly whether infected or uninfected foliage was placed in the olfactometer $\left(\chi^{2}=0\right.$, df $=1$, $P=1$ ). Of 20 individuals tested against each type of foliage, 12 individuals $(60 \%)$ responded to infected foliage from injected plants while 13 individuals $(65.00 \%)$ gave a response to the smell of uninfected foliage from uninjected plants. Among responsive aphids, nine green peach aphids $(45.00 \%)$ showed a positive response toward infected foliage, while six green peach aphids $(30.00 \%)$ showed a positive response to uninfected foliage. As with the response frequency, the difference between positive and negative responses was not statistically significant $\left(\chi^{2}=1.1, \mathrm{df}=1, P=0.2881\right)$.

Similarly, green peach aphids did not display significant discrimination between infected and uninfected foliage when both types of foliage came from plants which had received traumatic injections: of 20 trials for each type of foliage, 15 green peach aphids $(75.00 \%)$ were responsive toward infected foliage, while 14 green peach aphids $(70.00 \%)$ were responsive toward the uninfected foliage $\left(\chi^{2}=0\right.$, df $\left.=1, P=1\right)$. Of the 15 green peach aphids that responded to infected foliage, 6 $(40.00 \%)$ gave a positive response. Of the 14 green peach aphids that responded to uninfected foliage, $6(42.86 \%)$ gave a positive response $\left(\chi^{2}<0.0001\right.$, df $\left.=1, P=1\right)$.

\section{Insect recruitment to foliage from infected plants in artificial arenas}

Colorado potato beetle did not display a significant preference for either infected or uninfected potato plants $(t=-0.22$, $\mathrm{df}=16, P=0.8267$ ). On average, $2.33 \pm 0.49$ beetles (mean \pm $\mathrm{SE}$ ) colonized the plants, while the rest remained elsewhere in the arenas.

Among the individually tested green peach aphids, there was a statistically significant preference for Dickeya-infected foliage: 27 individuals chose foliage from infected potato plants while only 13 individuals chose foliage from uninfected plants (Fig. 4A) $\left(\chi^{2}=4.9\right.$, df $\left.=1, P=0.0269\right)$. This trend reversed when aphids were released in groups of 10 (Fig. 4B) $(Z=-8.1, \mathrm{df}=1, P<0.0001)$. The difference between aphid choices when expressed as a percentage differed significantly between isolated individuals and those in groups $\left(\chi^{2}=23\right.$, df $=1, P<0.0001)$.

\section{Laboratory uptake and transmission of $D$. dianthicola}

Neither green peach aphids nor Colorado potato beetles transmitted Dickeya spp., because no plants were found to have acquired Dickeya spp. following insect feeding and incubation. One Colorado potato beetle sample tested positive through PCR for Dickeya spp. However, that sample had been collected from a single dead male beetle from a control trial, and the beetle suspension from this individual failed to produce cavity-forming bacterial colonies on CVP medium. All other samples, including all of the beetles feeding on infected

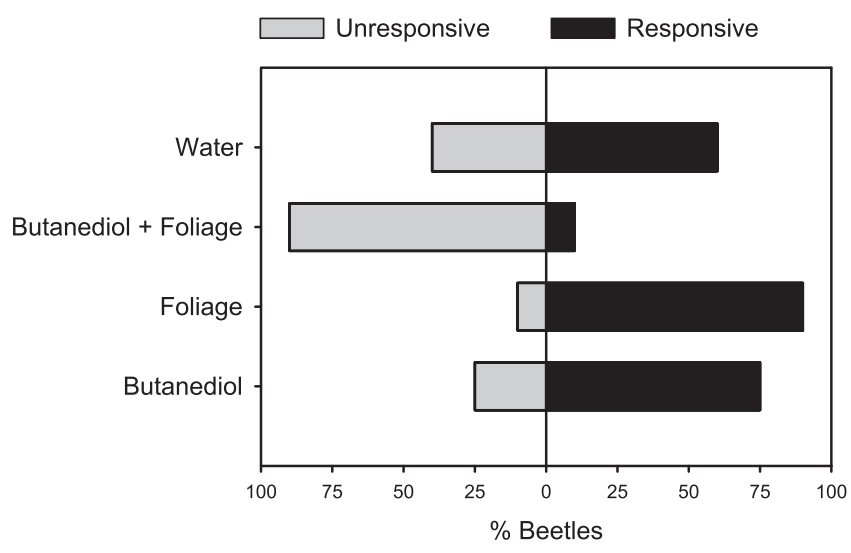

FIGURE 3

Percentage of adult Colorado potato beetles moving upwind when exposed to different odors in a wind tunnel $(n=20)$. 
plants, tested negative using PCR and, in the case of the beetles, also using plating.

Two beetles died during the experiment: one male from a control trial and a female from an infected trial. As such, there does not appear to be any difference in mortality between infected and control treatments. With green peach aphids, 167 individuals from infected trials died, while 121 green peach aphids died during the control trials. Although this appears to be a high number, aphids have a very short life span. Therefore, high mortality was expected. An ANOVA test showed that the difference in mortalities lacked statistical significance $(F=1.16$, df $=1,20, P=0.295)$.

\section{Field uptake and transmission of $D$. dianthicola}

Insecticide treatments had an impact on Colorado potato beetles (Fig. 5). Due to beetle phenology, the differences depended on the dates of sampling, as indicated by significant interactions between the treatment and the sampling date for egg masses $(F=3.46$, df $=15,80, P=0.0002)$, small larvae $(F=2.90, \mathrm{df}=15,80, P=0.0011)$, large larvae $(F=19.60, \mathrm{df}$ $=15,80, P<0.0001)$, and adults $(F=3.50$, df $=15,80, P=$ $0.0001)$. However, as expected, there was an overall reduction in the Colorado potato beetle abundance (Fig. 5). Defoliation
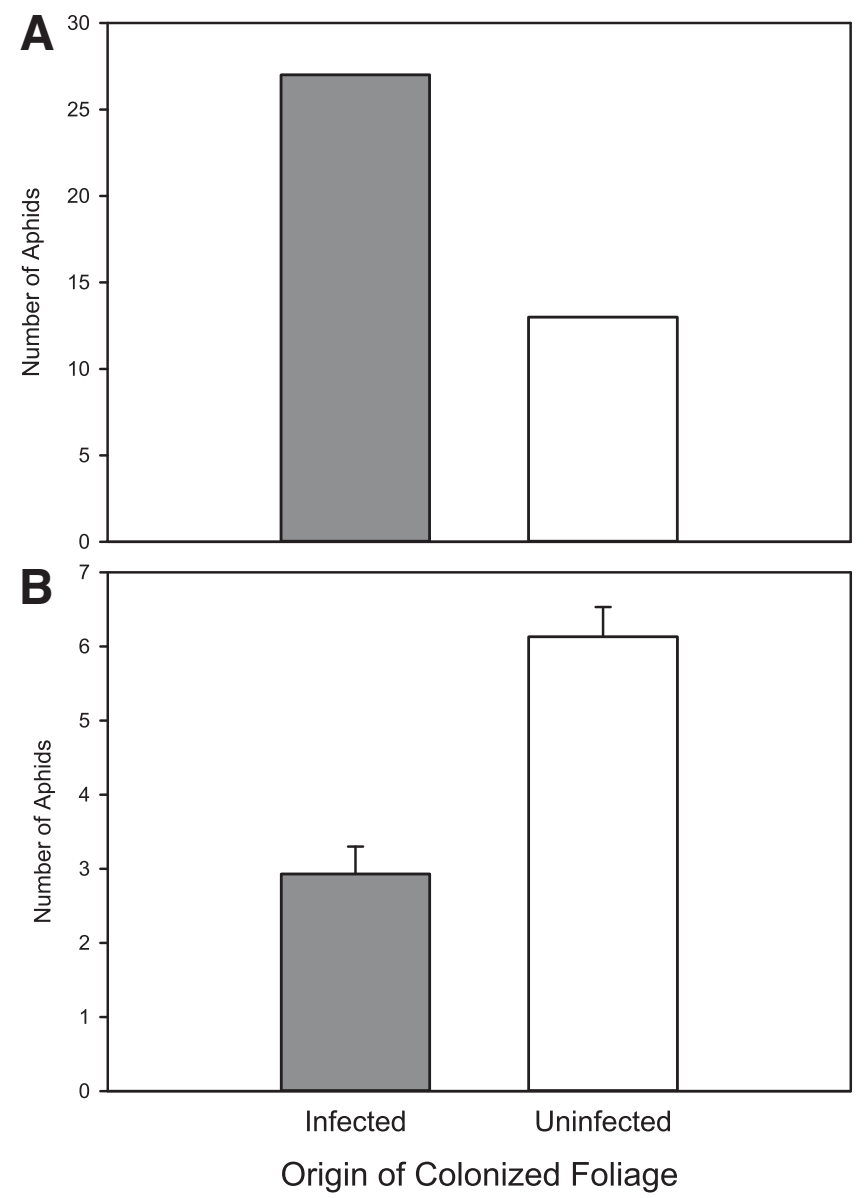

\section{FIGURE 4}

Colonization by green peach aphids of potato leaflets excised from potato plants infected and uninfected by Dickeya dianthicola. Experiments were conducted in laboratory arenas made of 100-by-15-mm Petri dishes lined with moistened paper towels $(n=30)$. A, Individually released aphids and $\mathbf{B}$, aphids released in groups of 10 . followed beetle numbers in being higher on plots that were not treated with spinosad $(F=5.18, \mathrm{df}=9,64, P<0.0001)$ (Fig. 6). Aphid numbers were very low throughout the season $(0.93 \pm 0.29$ individuals per plant per date $)$. Neither treatment effect on aphids $(F=0.20$, df $=3,16, P=0.8976)$ nor its interaction with the day of sampling were statistically significant ( $F=0.70$, df $=12,64, P=0.7457)$. Based on Wilcoxon's tests, both beetle and aphid numbers were similar between the symptomatic and asymptomatic plants $(P<0.1)$.

In 2017 , no significant variation in the numbers of symptomatic plants was observed among the treatments $(F=0.22$, df $=$ $3,16, P=0.8813)$. Slightly over half of the 320 injected plants across all field treatments acquired visible symptoms (Supplementary Fig. S1). Of uninoculated plants, less than $10 \%$ developed symptoms of blackleg. The difference in symptom expression between injected and uninjected plants was significant $(F=43.04$, df $=1,127, P<0.0001)$. Stepwise multiple regression showed that only the abundance of adult Colorado potato beetles had a significant negative effect on the number of symptomatic plants $(F=9.45$, df $=1,78, P<0.01)$. More adult beetles resulted in fewer symptomatic plants on a plot

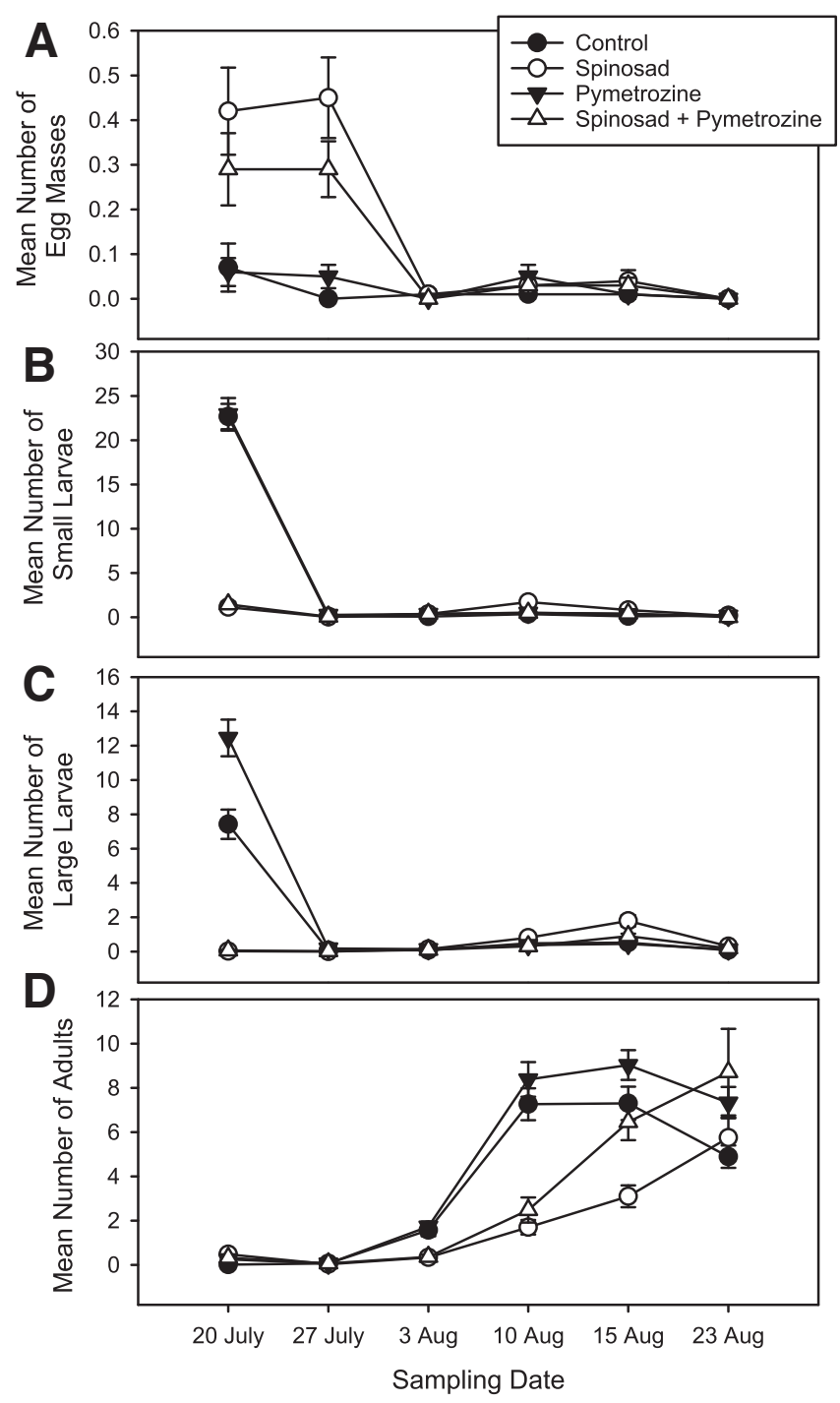

FIGURE 5

Abundances of different Colorado potato beetle life stages determined by visual observations on experimental field potato plots treated with different insecticides in 2017. Mean number of A, egg masses; B, small larvae; C, large larvae; and D, adults. 
(Fig. 7). However, that relationship explained only $10 \%$ of the variation. It is likely that we observed a spurious correlation caused by the decline in numbers of overwintered adults due to their old age, while the number of symptomatic plants increased as the season progressed. Neither aphids nor larval Colorado potato beetles had any significant relationship with the number of symptomatic plants over the 2017 field season.

Of the 73 tubers harvested in 2017 from injected plants and grown in greenhouse conditions, only three tubers failed to germinate: two tubers (one from a symptomatic plant and one from an asymptomatic plant) came from a field which had been treated against aphids only, while a third tuber came from a symptomatic plant from a control plot. When the remains of those tubers were tested using PCR, none of them came back positive for Dickeya spp. Of the remaining 70 plants, none displayed any symptoms associated with Dickeya infections. Similarly, only two plants planted back in the field displayed symptoms. Both were grown from tubers harvested from fields sprayed with pymetrozine to control aphids. PCR of the tubers harvested in 2017 detected Dickeya, but

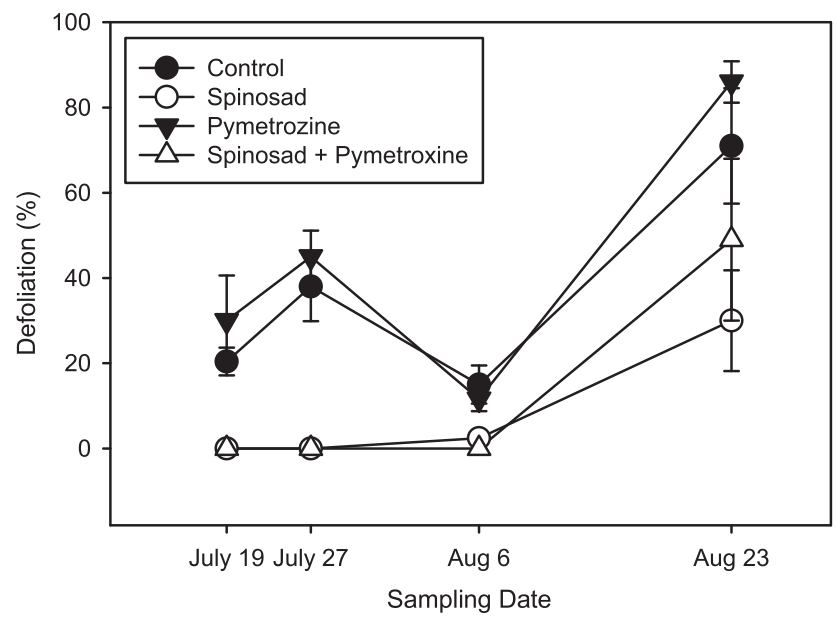

FIGURE 6

Defoliation of experimental field potato plots treated with different insecticides in 2017.

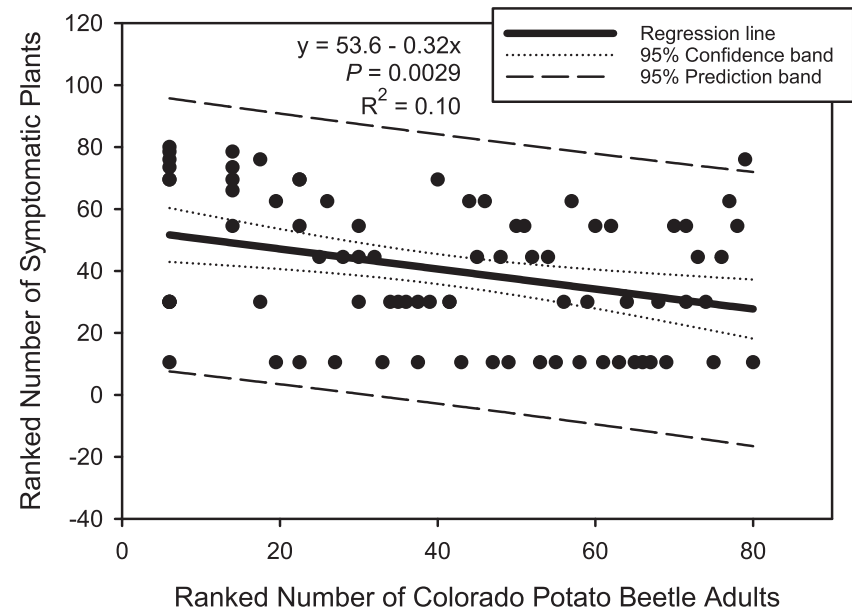

FIGURE 7

Relationship between the abundance of adult Colorado potato beetles and the number of potato plants expressing blackleg symptoms within each field plot in 2017 . Trendline was constructed based on stepwise multiple regression conducted on rank-transformed data. seldomly. Among the injected plants, $7.68 \%$ from symptomatic plants and $6.00 \%$ from asymptomatic plants tested positive. Among uninjected plants, $6.90 \%$ from symptomatic plants and $10.00 \%$ from asymptomatic plants were positive. Plant status did not affect the percentage of infected tubers $\left(\chi^{2}=0.22\right.$, df $\left.=1, P=0.632\right)$. Only one or two daughter tubers from each plant had tested positive for Dickeya spp., while the remaining daughter tubers remained uninfected.

Tubers harvested from the field in 2018 yielded fewer positive results, possibly because of the dry conditions early in the season (Supplementary Table S1). In total, 213 tubers were tested, of which 200 came from uninjected plants and 13 came from injected plants. Of those tubers, PCR showed that only three were infected with Dickeya spp. Two of those tubers came from a single plot treated with spinosad. One of those tubers came from an injected plant while the other was from a plant that had not been injected. The third tuber that tested positive for Dickeya spp. originated from an injected plant from a control plot.

\section{DISCUSSION}

There was no evidence that two of the most ubiquitous and damaging pests of potato, the Colorado potato beetle and the green peach aphid, contributed to the spread of $D$. dianthicola among potato plants. Results of different experiments conducted in the laboratory and in the field consistently supported this conclusion. Latent infections are usually characterized by low density of bacteria in plant tissues (Czajkowski et al. 2015); therefore, it is theoretically possible that some of the transmission was not detected. However, methods used in the present study have a good record of success and serve as current industry standards for Dickeya diagnostics (Czajkowski et al. 2015; Potrykus et al. 2014; Tsror et al. 2012). Furthermore, results were highly consistent among PCR assays, plating on CVP media, and visual observations of symptom expression in plants. Therefore, the probability of obtaining false negatives was low, and our results conformed to a generally accepted definition of an uninfected plant.

D. dianthicola displayed an experimentally detectable capacity to modify insect behavior. However, its effects were small and sporadic. Therefore, it is unlikely that changes observed in the present study will translate to a significant increase in the transmission of this bacterium between potato plants under field conditions by either insect species tested.

Colorado potato beetles, which are the most prominent defoliators in most potato agroecosystems, did not discriminate between foliage from infected and uninfected plants in either olfactometry or recruitment experiments. This may benefit $D$. dianthicola, in that Colorado potato beetles do not preferentially destroy infected plants, thus depriving the bacteria of their hosts. However, it also diminishes the importance of Colorado potato beetles as vectors for $D$. dianthicola because contact between beetles and bacteria essentially comes down to random chance and there is no hostvector coevolutionary relationship.

Although a Dickeya volatile metabolite 2,3-butanediol alone did not affect Colorado potato beetle behavior, its combination with potato foliage elicited a strong negative response. Colorado potato beetles are attracted to specific blends of volatiles emitted by potato plants rather than to individual chemicals (Dickens 2000). Earlier studies also showed differential Colorado potato beetle attraction to potato plants depending on plant age, mechanical damage, herbivory, and treatments with volicitin and methyl jasmonate (Bolter et al. 1997; Landolt 
et al. 1999). Therefore, a change in behavior following an alteration in blend composition is not surprising. The volatile combination of potato foliage and 2,3-butanediol may mimic the odor of potato vegetation in the late stages of infection, where the health of the host is rapidly depleted due to maceration of the vascular tissues by $D$. dianthicola. If this is true, then Colorado potato beetles avoid plants or parts of plants where significant wet necrosis and decomposition are present.

The observed behavior of Colorado potato beetle exposed to 2,3-butanediol in the present study is different from behaviors reported for drosophilid flies (Becher et al. 2012) and the sorghum chafer, $P$. interrupta (Bengtsson et al. 2009). This volatile is also employed by male medflies (Ceratitis capitata (Wiedemann)), who secrete it as a component of their aggregation pheromones during lekking (Sollai et al. 2018). However, Colorado potato beetles feed on live potato foliage and not fermenting plant material. Therefore, signs of decay are likely to indicate poor-quality host plants. Presence of a strong additional odor may have also masked the odors of green leaf volatiles otherwise attractive to Colorado potato beetles (Hilker and McNeil 2008).

Green peach aphids differed in their discrimination ability between the recruitment and the olfactometry experiments. In the olfactometry experiment, no significant discrimination was observed. Because aphids used in the olfactometry experiment were unable to make physical contact with the provided foliage, this suggests that foliar olfactory cues were not sufficient for aphids to discriminate between plants with and without $D$. dianthicola infections. Previous studies have also shown the importance of visual, gustatory, and tactile cues during host selection (Giordanengo et al. 2010; Hori 1999; Pelletier 1990; Powell et al. 2006).

In the recruitment experiment, the difference in feeding preferences between aphids acting alone and those in groups may be due to an interaction between plant susceptibility to insect pests and social facilitation. Aphids employ a compositionally complex watery saliva that contains, among other substances, calcium-scavenging proteins, which prevent phloem sieve occlusion (Will et al. 2007), and detoxifying enzymes such as peroxidase, which combat oxidative stressors (Giordanengo et al. 2010; Will et al. 2013). Several species, including the green peach aphid, have also been noted to selectively suppress genes relating to more efficient jasmonic acid-dependent chemical defenses, although less effective salicylic acid-dependent pathways remain uninhibited (Giordanengo et al. 2010; Moran and Thompson 2001; Walling 2008). The nutritional quality of a plant's phloem may also be subject to modification by aphids, although this ability is not present within all species (Sandström et al. 2000). This change is systemic within these plants, and strains of this aphid which are unable to induce this nutritional modification display reduced growth and reproduction (Dorschner et al. 1987; Sandström et al. 2000).

It has been shown that plants which have been previously infested by conspecifics support aphids better than those which have not been fed on before (Civolani et al. 2010; Dugravot et al. 2007; Takemoto et al. 2013). For example, potato aphid M. euphorbiae (Thomas) (Ameline et al. 2007), cowpea aphid Aphis craccivora (Koch) (Pettersson et al. 1998), and the damson-hop aphid Phorodon humuli (Schrank) (Campbell et al. 1993) preferred plants previously infested by conspecifics to undamaged plants. Also, preinfestation by conspecifics resulted in longer periods of phloem ingestion in $M$. persicae (Civolani et al. 2010; Dugravot et al. 2007). Because D. dianthicola metabolizes nutrients from the host plant and impairs the flow of phloem sap on which aphids feed through destruction of the host's vascular tissues (Effantin et al. 2011; Toth et al. 2003), such aphid-manipulated uninfected hosts may be preferable when conspecifics are present. However, in the absence of conspecifics, a host whose physiological defenses have been compromised by a bacterial infection may be more suitable for individual aphids. Similarly, modulation of aphid attraction to host plants in a density-dependent manner has been earlier demonstrated for the bird cherry and oat aphid Rhopalosiphum padi (L.) (Pettersson et al. 1995), and for the cowpea aphid (Pettersson et al. 1998).

Neither Colorado potato beetles nor green peach aphids demonstrated an ability to acquire and transmit $D$. dianthicola between potato plants during laboratory experiments. Although a single Colorado potato beetle sample tested positive while using PCR, the sample had come from a control trial. Furthermore, the sample's bacterial suspension failed to produce cavities within CVP medium, indicating that it did not contain culturable pectolytic bacteria. Therefore, the reported PCR result is considered to be a false positive.

Neither insect species displayed a significant difference in mortalities between the individuals feeding on infected foliage versus those feeding on uninfected foliage. Given that the minimum infective dose of $D$. dadantii needed to elicit septicemia within pea aphid Acyrthosiphon pisum is just 10 cells (Grenier et al. 2006), it would be expected that, if either insect were susceptible to infection by $D$. dianthicola, they would show a marked increase in mortality following consumption of infected foliage. However, that was not observed. Our results corroborate the findings by Grenier et al. (2006), who showed that D. dadantii is not a generalist entomopathogen. Of the insects tested, only the pea aphid displayed septicemia after ingesting $D$. dadantii, whereas the vinegar fly Drosophila melanogaster (Meigen), the cotton leaf-worm Spodoptera oryzae (Boisduval), and the rice weevil Sitophilus oryzae (L.) suffered no mortalities through ingestion. Emergence of Dickyea dadantii from the gut lumen of the infected aphids into their coelomic cavity is achieved with the aid of Cyt toxins homologous to those produced by Bacillus thuringiensis (Berliner) (Costechareyre et al. 2012; Grenier et al. 2006). These genes are likely the result of horizontal gene transfer by a Gram-positive donor bacterium and are not found within genus Pectobacterium, explaining, at least in part, the difference in virulence between these sometimes cooccurring bacteria (Costechareyre et al. 2012; Grenier et al. 2006). The CytABCD proteins are present in multiple Dickeya spp. and strains. Based on their homology with Bt toxins, it is very likely that the varying clusters target different insect species. No genome sequence is available for the $D$. dianthicola strain ME30 that was used in the present study. However, D. dianthicola strain ME23 is fully sequenced and contains a cytABCD cluster that is quite different from the $D$. dadantii cluster (Ma et al. 2019). This suggests that possible insect pathogenicity is also different between the two bacterial species.

In the field, the abundances of Colorado potato beetles and potato-colonizing aphids did not differ significantly between infected and uninfected plants. This is in line with the pattern of behavior observed in laboratory experiments.

Very little disease spread was observed across all treatments during both seasons, even with the heavy defoliation caused by Colorado potato beetles. Wounds are known to serve as sites of infection by Dickeya spp. (Czajkowski et al. 2011). Wounded plant tissues release jasmonic acid, along with other signaling molecules, to initiate the launch of physiological defenses against herbivores and pathogens (Dammann et al. 1997; Moran and Thompson 2001; Reymond et al. 2000). Dickeya cells display strong positive chemotaxis toward 
jasmonic acid, allowing them to locate sites of entry into potential hosts (Reverchon and Nasser 2013). However, once inside a plant, Dickeya cells face physiological plant defenses that interfere with successful induction of systemic infection (Ngadze et al. 2012; Reverchon and Nasser 2013). The feeding activities of herbivorous insects can also elicit plant defense responses that can impair the growth of phytopathogens (De Vos et al. 2006; Kanno and Fujita 2003; Kanno et al. 2005; Mayer et al. 2002). Therefore, even if the damage caused by Colorado potato beetles could have increased the number of points of entry for $D$. dianthicola, additional factors such as the physiological response of plants to infection and possible cross-resistance between antiherbivore plant defenses and $D$. dianthicola may have complicated successful spread of the bacterium in the field. Thus, feeding by Colorado potato beetles does not appear to facilitate the spread of $D$. dianthicola under field conditions.

During both field seasons, aphid abundances were low. Coupled with the low frequency of infection among harvested tubers from all treatments, this prevents us from making any accurate conclusions about the effect of aphids on $D$. dianthicola transmission in the field.

Regardless of insect activity, D. dianthicola did not appear to be highly contagious. In part, the low frequency of infection detected among tubers harvested during both years may be explained by dry conditions (Supplementary Table S1). These bacteria are reliant on water films to travel within soil and be taken up into roots and tuber lenticels (Czajkowski et al. 2010b; Toth et al. 2003), and symptom expression among plants which harbor Dickeya spp. varies depending on the growing conditions (Czajkowski et al. 2011; Tsror et al. 2009). Supplemental irrigation was used to bring up weekly precipitation to at least $25 \mathrm{~mm}$ yet the spread of infection between plants was still low. Therefore, it is likely that the low transmission rates could not be attributed to dry conditions alone.

It appeared that $D$. dianthicola often had difficulty translocating within plants following stem injections. It was not unusual to see an area of apparently suberized brownish tissue surrounding the black necrotic lesion formed around the site of injection in the field. Similarly, Czajkowski et al. (2010a) found that foliar inoculations of potato plants under greenhouse conditions rarely resulted in the infection of daughter tubers, perhaps due, in part, to internal physiological barriers such as that posed by the junction between the petiole base and the plant's stem. Lack of systemic spread throughout injected plants may have been at least partially responsible for the observed lack of $D$. dianthicola transmission from injected to uninjected plants. Because both Colorado potato beetles and aphids feed mostly on potato leaves rather than on stems, their exposure to bacterial inoculum may have been low even on injected symptomatic plants.

Ongoing work by Hao et al. (2017) has also demonstrated that some potato cultivars have at least partial resistance to $D$. dianthicola ME30. Although the potato cultivars chosen for our experiments (Superior and Katahdin) are known to be susceptible to infection (Hao et al. 2017) (unpublished observations), not all plants injected with $D$. dianthicola in the field acquired active, lethal infections. Therefore, it is possible that the plants did possess some limited resistance against $D$. dianthicola under the conditions of our study.

Although we did not observe any transmission of $D$. dianthicola by two of the most common and devastating insect pests of potato, insect contribution to the spread of this pathogen cannot be completely ruled out. For example, seedcorn maggots (Delia platura (Meigen)) are known to infest rotting or poorly healed seed potato tubers before plants emerge from the soil. Therefore, they may be more relevant for Dickeya transmission than aboveground pests, especially because Delia spp. appear to have mutualism with at least some Pectobacterium spp. (Rossmann et al. 2018; Welte et al. 2015). Further investigations are needed to elucidate their potential epidemiological role, as well possible contributions by other insect species.

\section{ACKNOWLEDGMENTS}

We thank A. Buzza, J. Rose, M. Smith, A. Landry, and R. Wlodkowski for technical assistance.

\section{LITERATURE CITED}

Alyokhin, A., Porter, G., Groden, E., and Drummond, F. 2005. Colorado potato beetle response to soil amendments: A case in support of the mineral balance hypothesis? Agric. Ecosyst. Environ. 109:234-244.

Alyokhin, A., and Sewell, G. 2003. On-soil movement and plant colonization by walking wingless morphs of three aphid species (Homoptera: Aphididae) in greenhouse arenas. Environ. Entomol. 32:1393-1398.

Ameline, A., Couty, A., Dugravot, S., Campan, E., Dubois, F., and Giordanengo, P. 2007. Immediate alteration of Macrosiphum euphorbiae host plant-selection behavior after biotic and abiotic damage inflicted to potato plants. Entomol. Exp. Appl. 123:129-137.

Baur, R., Städler, E., Monde, K., and Takasugi, M. 1998. Phytoalexins from Brassica (Cruciferae) as oviposition stimulants for the cabbage root fly, Delia radicum. Chemoecology 8:163-168.

Becher, P. G., Flick, G., Rozpedowska, E., Schmidt, A., Hagman, A., Lebreton, S., Larsson, M. C., Hansson, B. S., Piškur, J., Witzgall, P., and Bengtsson, M. 2012. Yeast, not fruit volatiles mediate Drosophila melanogaster attraction, oviposition and development. Funct. Ecol. 26:822-828.

Bengtsson, J. M., Wolde-Hawariat, Y., Khbaish, H., Negash, M., Jembere, B., Seyoum, E., Hansson, B. S., Larsson, M. C., and Hillbur, Y. 2009 Field attractants for Pachnoda interrupta selected by means of GCEAD and single sensillum screening. J. Chem. Ecol. 35:1063-1076.

Bolter, C. J., Dicke, M., van Loon, J. J. A., Visser, J. H., and Posthumus, M. A. 1997. Attraction of Colorado potato beetle to herbivore-damaged plants during herbivory and after its termination. J. Chem. Ecol. 23:1003-1023.

Booth, E., and Alyokhin, A. 2016. Colorado potato beetle response to potato plants infected with Potato virus $Y$ and Potato leafroll virus. Am. J. Potato Res. 93:213-223.

Borman, E. K., Stuart, C. A., and Wheeler, K. M. 1944. Taxonomy of the family Enterobacteriaceae. J. Bacteriol. 48:351-367.

Campbell, C. A. M., Pettersson, J., Pickett, J. A., Wadhams, L. J., and Woodcock, C. M. 1993. Spring migration of damson-hop aphid, Phorodon humuli (Homoptera: Aphididae), and summer host plant-derived semiochemicals released on feeding. J. Chem. Ecol. 19:1569-1576.

Capinera, J. L. 2017. Featured Creatures: Green peach aphid-Myzus persicae (Sulzer). University of Florida, Institute of Food and Agricultural Sciences. http://entnemdept.ufl.edu/creatures/veg/aphid/ green_peach_aphid.htm

Charkowski, A. O. 2018. The changing face of bacterial soft-rot diseases. Annu. Rev. Phytopathol. 56:269-288.

Civolani, S., Marchetti, E., Chicca, M., Castaldelli, C., Rossi, R., Pasqualini, E., Dindo, M. L., Baronio, P., and Leis, M. 2010. Probing behavior of Myzus persicae on tomato plants containing $M i$ gene or BTH-treated evaluated by electrical penetration graph. Bull. Insectol. 63:265-271.

Costechareyre, D., Balmand, S., Condemine, G., and Rahbé, Y. 2012. Dickeya dadantii, a plant pathogenic bacterium producing cyt-like entomotoxins, causes septicemia in the pea aphid Acyrthosiphon pisum. PLoS One 7:e30702.

Czajkowski, R., de Boer, W. J., van Veen, J. A., and van der Wolf, J. M. 2010a. Downward vascular translocation of a green fluorescent proteintagged strain of Dickeya sp. (Biovar 3) from stem and leaf inoculation sites on potato. Phytopathology 100:1128-1137. 
Czajkowski, R., de Boer, W. J., Velvis, H., and van der Wolf, J. M. 2010b. Systemic colonization of potato plants by a soilborne, green fluorescent protein-tagged strain of Dickeya sp. biovar 3 . Phytopathology 100:134-142.

Czajkowski, R., Pérombelon, M. C. M., Jafra, S., Lojkowska, E., Potrykus, M., van der Wolf, J. M., and Sledz, W. 2015. Detection, identification and differentiation of Pectobacterium and Dickeya species causing potato blackleg and tuber soft rot: A review. Ann. Appl. Biol. 166:18-38.

Czajkowski, R., Pérombelon, M. C. M., van Veen, J. A., and van der Wolf, J. M. 2011. Control of blackleg and tuber soft rot of potato caused by Pectobacterium and Dickeya species: A review. Plant Pathol. J. 60:999-1013.

Dammann, C., Rojo, E., and Sánchez-Serrano, J. J. 1997. Abscisic acid and jasmonic acid activate wound-inducible genes in potato through separate, organ-specific signal transduction pathways. Plant J. 11:773-782.

De Vos, M., Van Zaanen, W., Koornneef, A., Korzelius, J. P., Dicke, M., Van Loon, L. C., and Pieterse, C. M. J. 2006. Herbivore-induced resistance against microbial pathogens in Arabidopsis. Plant Physiol. 142:352-363.

Dickens, J. C. 2000. Orientation of Colorado potato beetle to natural and synthetic blends of volatiles emitted by potato plants. Agric. For. Entomol. 2:167-172.

Dorschner, K. W., Ryan, J. D., Johnson, R. C., and Eikenbary, R. D. 1987. Modification of host nitrogen levels by the greenbug (Homoptera: Aphididae): Its role in resistance of winter wheat to aphids. Environ. Entomol. 16:1007-1011.

Dugravot, S., Brunissen, L., Létocart, E., Tjallingii, W. F., Vincent, C., Giordanengo, P., and Cherqui, A. 2007. Local and systemic responses induced by aphids in Solanum tuberosum plants. Entomol. Exp. Appl. 123:271-277.

Effantin, G., Rivasseau, C., Gromova, M., Bligny, R., and HugouvieuxCotte-Pattat, N. 2011. Massive production of butanediol during plant infection by phytopathogenic bacteria of the genera Dickeya and Pectobacterium. Mol. Microbiol. 82:988-997.

Esker, P. D., and Nutter, F. W., Jr. 2003. Temporal dynamics of corn flea beetle populations infested with Pantoea stewartii, causal agent of Stewart's disease of corn. Phytopathology 93:210-218.

Galimberti, A., and Alyokhin, A. 2018. Lethal and sublethal effects of mineral oil on potato pests. J. Econ. Entomol. 111:1261-1267.

Giordanengo, P., Brunissen, L., Rusterucci, C., Vincent, C., van Bel, A., Dinant, S., Girousse, C., Faucher, M., and Bonnemain, J.-L. 2010. Compatible plant-aphid interactions: How aphids manipulate plant responses. C. R. Biol. 333:516-523.

Grenier, A., Duport, G., Pagès, S., Condemine, G., and Rahbé, Y. 2006. The phytopathogen Dickeya dadantii (Erwinia chrysanthemi 3937) is a pathogen of the pea aphid. Appl. Environ. Microbiol. 72:1956-1965.

Hao, J., Porter, G., Ge, T., Dankwa, A., Marangoni, N., and Giggie, E. 2017. Research Progress Report to Maine Potato Board: Screening Potato Varieties for Pink Rot, Bacterial Soft Rot, and Dry Rot Resistance. https://www.mainepotatoes.com/wp-content/uploads/2019/ 04/Screening-Potato-Varieties-for-Pink-Rot-Bacterial-Soft-Rot-and-DryRot-Resistance-1.pdf

Heiduk, A., Brake, I., Tschirnhaus, M. V., Haenni, J.-P., Miller, R., Hash, J., Prieto-Benítez, S., Jürgens, A., Johnson, S. D., Schulz, S., LiedeSchumann, S., Meve, U., and Dötterl, S. 2017. Floral scent and pollinators of Ceropegia trap flowers. Flora 232:169-182.

Hélias, V., Hamon, P., Huchet, E., Wolf, J. V. D., and Andrivon, D. 2011. Two new effective semi-selective crystal violet pectate (CVP) media for isolation of Pectobacterium and Dickeya. Plant Pathol. 61:339-345.

Hilker, M., and McNeil, J. N. 2008. Chemical and behavioural ecology in insect parasitoids: How to behave optimally in a complex odourous environment. Pages 92-112 in: Behavioural Ecology of Insect Parasitoids. É. Wajnberg, C. Bernstein, and J. van Alphen, eds. WileyBlackwell, Malden, MA, U.S.A.

Hori, M. 1999. Role of host plant odors in the host finding behaviors of aphids. Appl. Entomol. Zool. 34:293-298.

Jiang, H. H., Hao, J., Johnson, S. B., Brueggeman, R. S., and Secor, G. 2016. First report of Dickeya dianthicola causing blackleg and bacterial soft rot on potato in Maine. Plant Dis. 100:2320.
Kanno, H., and Fujita, Y. 2003. Induced systemic resistance to rice blast fungus in rice plants infected by white-backed planthopper. Entomol. Exp. Appl. 107:155-158.

Kanno, H., Satoh, M., Kimura, T., and Fujita, Y. 2005. Some aspects of induced resistance to rice blast fungus, Magnaporthe grisea, in rice plant infested by white-backed planthopper, Sogatella furcifera. Appl. Entomol. Zool. 40:91-97.

Kloepper, J. W., Brewer, J. W., and Harrison, M. D. 1981. Insect transmission of Erwinia carotovora var. carotovora and Erwinia carotovora var. atroseptica to potato plants in the field. Am. Potato J. 58:165-175.

Landolt, P. J., Tumlinson, J. H., and Alborn, D. H. 1999. Attraction of Colorado potato beetle (Coleoptera: Chrysomelidae) to damaged and chemically induced potato plants. Environ. Entomol. 28:973-978.

Laurila, J., Ahola, V., Lehtinen, A., Joutsjoki, T., and Hannukkala, A. 2008. Characterization of Dickeya strains isolated from potato and river water samples in Finland. Eur. J. Plant Pathol. 122:213-225.

Ma, B., Hibbing, M. E., Kim, H., Reedy, R. M., Yedidia, I., Breuer, J., Breuer, J., Glasner, J. D., Perna, N. T., Kelman, A., and Charkowski, A. O. 2007. Host range and molecular phylogenies of the soft rot enterobacterial genera Pectobacterium and Dickeya. Phytopathol. 97:1150-1163

Ma, X., Perna, N. T., Glasner, J. D., Hao, J., Johnson, S., Nasaruddin, A. S., Charkowski, A. O., Wu, S., Fei, Z., Perry, K. L., Stodghill, P., and Swingle, B. 2019. Complete genome sequence of Dickeya dianthicola ME23, a pathogen causing blackleg and soft rot diseases of potato. Microbiol. Resour. Announce. 8:e01526-18.

Mayer, R. T., Inbar, M., McKenzie, C. L., Shatters, R., Borowicz, V., Albrecht, U., Powell, C. A., and Doostdar, H. 2002. Multitrophic interactions of the silverleaf whitefly, host plants, competing herbivores, and phytopathogens. Arch. Insect Biochem. 51:151-169.

Menelas, B., Block, C. C., Esker, P. D., and Nutter, F. W., Jr. 2006. Quantifying the feeding periods required by corn flea beetles to acquire and transmit Pantoea stewartii. Plant Dis. 90:319-324.

Molina, J. J., Harrison, M. D., and Brewer, J. W. 1974. Transmission of Erwinia carotovora var. atroseptica by Drosophila melanogaster Meig. I. Acquisition and transmission of bacterium. Am. Potato J. 51:245-250.

Moran, P. J., and Thompson, G. A. 2001. Molecular responses to aphid feeding in Arabidopsis in relation to plant defense pathways. Plant Physiol. 125:1074-1085.

Nadarasah, G., and Stavrinides, J. 2011. Insects as alternative hosts for phytopathogenic bacteria. FEMS Microbiol. Rev. 35:555-575.

Narayandas, G., and Alyokhin, A. 2006a. Diurnal patterns in host finding by potato aphids, Macrosiphum euphorbiae (Homoptera: Aphididae). J. Insect Behav. 19:347-356.

Narayandas, G., and Alyokhin, A. 2006b. Interplant movement of potato aphid (Homoptera: Aphididae) in response to environmental stimuli. Environ. Entomol. 35:733-739.

Nassar, A., Darrasse, A., Lemattre, M., Kotoujansky, A., Dervin, C., Vedel, R., and Bertheau, Y. 1996. Characterization of Erwinia chrysanthemi by pectinolytic isozyme polymorphism and restriction fragment length polymorphism analysis of PCR-amplifies fragments of pel genes. Appl. Environ. Microbiol. 62:2228-2235.

NPC. 2017. Protocol for detection of Dickeya and Pectobacterium in potato tubers, stems, or irrigation water. NPC Seed Certification Sub-Committee. National Potato Council. https://www.aphis.usda.gov/plant_health/plant pest_info/potato/downloads/dickeya/npc-dickeya-protocol.pdf

Ngadze, E., Icishahayo, D., Coutinho, T. A., and van der Waals, J. E. 2012. Role of polyphenol oxidase, peroxidase, phenylalanine ammonia lyase, chlorogenic acid, and total soluble phenols in resistance of potatoes to soft rot. Plant Dis. 96:186-192.

Pelletier, Y. 1990. The role of the color of the substratum on the initiation of the probing behavior in Myzus persicae (Sulzer) and Macrosiphum euphorbiae (Thomas) (Homoptera: Aphididae). Can. J. Zool. 68:694-698.

Pettersson, J., Karunaratne, S., Ahmed, E., and Kumar, V. 1998. The cowpea aphid, Aphis craccivora, host plant odours and pheromones. Entomol. Exp. Appl. 88:177-184.

Pettersson, J., Quiroz, A., Stephansson, D., and Niemeyer, H. M. 1995. Odour communication of Rhopalosiphum padi on grasses. Entomol. Exp. Appl. 76:325-328. 
Potrykus, M., Sledz, W., Golanowska, A., Slawiak, M., Binek, A., Motyka, A., Zoledowska, S., Czajkowski, R., and Lojkowska, E. 2014. Simultaneous detection of major blackleg and soft rot bacterial pathogens in potato by multiplex polymerase chain reaction. Ann. Appl. Biol. 165:474-487.

Powell, G., Tosh, C. R., and Hardie, J. 2006. Host plant selection by aphids: Behavioral, evolutionary, and applied perspectives. Annu. Rev. Entomol. 51:309-330.

Reverchon, S., and Nasser, W. 2013. Dickeya ecology, environment sensing and regulation of virulence programme. Environ. Microbiol. Rep. 5:622-636.

Reymond, P., Weber, H., Damond, M., and Farmer, E. E. 2000. Differential gene expression in response to mechanical wounding and insect feeding in Arabidopsis. Plant Cell 12:707-719.

Roper, M. C. 2011. Pantoea stewartii subsp. stewartii: Lessons learned from a xylem-dwelling pathogen of sweet corn. Mol. Plant Pathol. 12:628-637.

Rossmann, S., Dees, M. W., Perminow, J., Meadow, R., and Brurberg, M. B. 2018. Soft rot Enterobacteriaceae are carried by a large range of insect species in potato fields. Appl. Environ. Microbiol. 84:e00281-18.

Sandström, J., Telang, A., and Moran, N. A. 2000. Nutritional enhancement of host plants by aphids - a comparison of three aphid species on grasses. J. Insect Physiol. 46:33-40.

Sasu, M. A., Seidl-Adams, I., Wall, K., Winsor, J. A., and Stephenson, A. C. 2010. Floral transmission of Erwinia tracheiphila by cucumber beetles in wild Cucurbita pepo. Environ. Entomol. 39:140-148.

Shapiro, L., de Moraes, C. M., Stephenson, A. G., and Mescher, M. C. 2012. Pathogen effects on vegetative and floral odours mediate vector attraction and host exposure in a complex pathosystem. Ecol. Lett. 15:1430-1438.

Sollai, G., Solari, P., and Crnjar, R. 2018. Olfactory sensitivity to major, intermediate and trace components of sex pheromone in Ceratitis capitata is related to mating and circadian rhythm. J. Insect Physiol. 110:23-33.

Soto-Arias, J. P., Groves, R. L., and Barak, J. D. 2014. Transmission and retention of Salmonella enterica by phytophagous Hemipteran insects. Appl. Environ. Microbiol. 80:5447-5456.
Stavrinides, J., McCloskey, J. K., and Ochman, H. 2009. Pea aphid as both host and vector for the phytopathogenic bacterium Pseudomonas syringae. Appl. Environ. Microbiol. 75:2230-2235.

Takemoto, H., Uefune, M., Ozawa, R., Arimura, G.-I., and Takabayashi, J. 2013. Previous infestation of pea aphids Acyrthosiphon pisum on broad bean plants results in the increased performance of conspecific nymphs on the plants. J. Plant Interact. 8:370-374.

Toth, I. K., Bell, K. S., Holeva, M. C., and Birch, P. R. J. 2003. Soft rot erwiniae: From genes to genomes. Mol. Plant Pathol. 4:17-30.

Toth, I. K., van der Wolf, J. M., Saddler, G., Lojkowska, E., Hélias, V., Pirhonen, M., Tsror (Lahkim), L., and Elphinstone, J. G. 2011. Dickeya species: An emerging problem for potato production in Europe. Plant Pathol. 60:385-399.

Tsror (Lahkim), L., Erlich, O., Hazanovsky, M., Ben Daniel, B., Zig, U., and Lebiush, S. 2012. Detection of Dickeya spp. latent infection in potato seed tubers using PCR or ELISA and correlation with disease incidence in commercial field crops under hot-climate conditions. Plant Pathol. 61:161-168.

Tsror (Lahkim), L., Erlich, O., Lebiush, S., Hazanovsky, M., Zig, U., Slawiak, M., Grabe, G., van der Wolf, J. M., and van de Haar, J. J. 2009. Assessment of recent outbreaks of Dickeya sp. (syn. Erwinia chrysanthemi) slow wilt in potato crops in Israel. Eur. J. Plant Pathol. 123:311.

UMCE. 2016. Field Guide-Aphids. The University of Maine Cooperative Extension, Orono, ME, U.S.A.

Walling, L. L. 2008. Avoiding effective defenses: Strategies employed by phloem-feeding insects. Plant Physiol. 146:859-866.

Welte, C. U., de Graaf, R. M., van den Bosch, T. J. M., Op den Camp, H. J. M., van Dam, N. M., and Jetten, M. S. M. 2015. Plasmids from the gut microbiome of cabbage root fly larvae encode SaxA that catalyses the conversion of the plant toxin 2-phenylethyl isothiocyanate. Environ. Microbiol. 18:1379-1390.

Will, T., Furch, A. C. U., and Zimmermann, M. R. 2013. How phloemfeeding insects meet the challenge of phloem-located defenses. Plant Physiol. 4:1-12.

Will, T., Tjallingii, W. F., Thönnessen, A., and van Bel, A. J. E. 2007. Molecular sabotage of plant defense by aphid saliva. Proc. Natl. Acad. Sci. U.S.A. 104:10536-10541. 